\title{
Enhancement of Anthocyanin, Chlorophyll and Total Phenolic Content of Buckwheat Seedling By The Application of Led Light
}

\author{
Md Obyedul Kalam Azad ${ }^{1,2}$, Md Adnan ${ }^{1}$, Jimin Son ${ }^{1}$, Dong Ha Cho ${ }^{1}$ and Cheol Ho Park ${ }^{1 *}$ \\ ${ }^{1}$ College of Biomedical Science, Korea \\ ${ }^{2}$ Head of Research and Technology, Rentia Plant Factory, Korea
}

Received: 偹: December 10, 2018; Published: 眥: January 02, 2019

*Corresponding author: Cheol Ho Park, College of Biomedical Science, Chuncheon, Korea

\begin{abstract}
Different qualities of supplemental light emitting diode (LED) light were applied to enhance growth characteristics and bioactive compounds of buckwheat (Fagopyrum esculentum) seedlings. The wavelength of the LED lights was blue $470 \mathrm{~nm}$, red $660 \mathrm{~nm}$, blue + red (BR), far-red $740 \mathrm{~nm}$. The LED light treatments were applied after the emergence of two true leaves for 15 days and a control experiment was done without supplemental light. In this study, it is shown that supplemental BR light significantly increased plant height, node number, leaf number and plant fresh weight compared to control treatment. Far-red light increased stem length among the treatments. On the other hand, ascorbic acid, anthocyanin, total phenolic, and chlorophyll contents were significantly increased of buckwheat seedling grown under BR light compared to control.
\end{abstract}

Keywords: Ascorbic Acid; Anthocyanin; Buckwheat; Chlorophyll; LED light; Phenolic Compounds

Abbreviations: LED: Light emitting Diode; B+ R: Blue+ Red; R: Red; B: Blue; FR: Far-Red; RH: Relative Humidity; DMRT: Duncan’s Multiple Range Test; GAE: Gallic Acid Equivalent

\section{Introduction}

Sunlight is one of the most important factors for plant growth and development. However, in the glasshouse, sometimes the intensity of sunlight is not enough for plants to grow well because of continuous overcast, rainy days, greenhouse structures and coverings [1]. Artificial LED light has been strategically used to improve the plant food quality especially polyphenols contents of the plant in a controlled environment [2]. It is aforementioned in many reports that blue and red light are vital wavelengths for plant growth and development [3]. The absorption percentage of blue and red light is about $90 \%$ than the other spectra [4]. Light is the basic factor for growth and development of plant [5]. Supplemental light stimulates plant growth, promote stem extension [6], and increase a dry matter of pepper [5] radish and lettuce [7] and increase the leaf number of Alternanthera brasiliana [8]. Researchers are found that light quality affects the phytochemical concentration of plants $[9,10]$. It has been reported that blue light increased anthocyanin levels in tomato [11], carotenoids in coffee [12] and ascorbic acid in lettuce plants. On the other hand, Alokam et al observed that lower red / far-red ratio (R / FR), or more FR relative to $\mathrm{R}$ light decreased anthocyanin concentrations in potato and alpine crops [13]. These results have shown the viability of optimizing light quality in increasing phytochemical concentration and growth of plants.

The aim of this work was to determine which wavelengths of the supplemental light emitting diodes (LEDs) work best for buckwheat plants to obtain high-quality vegetables with enriched phytochemical concentrations in glass house condition.

\section{Materials and Method}

Buckwheat seeds were sown in a plastic tray and placed in a growth chamber maintaining temperature $250 \mathrm{C}$ and $\mathrm{RH} 50 \%$. After germination ( 3 days after seeding) all trays were moved to the greenhouse and waited up to distinct two true leaves and then two trays were subjected to each supplemental light treatment (as described below) inside the greenhouse.

\section{Supplemental Light Treatments}

A LED light panel consists of 20 LED sticks (20 LED bulbs on a stick) with the main controller $(33.5 \mathrm{~cm}$ wide, $27.5 \mathrm{~cm}$ long and $10 \mathrm{~cm}$ height, LPRS Series, Good Feeling Co. Ltd., Korea). LEDs light were placed horizontally $25 \mathrm{~cm}$ above the plant canopy. 
The experiments composed of five treatments with different supplementary LED wavelengths: red (R) $660 \mathrm{~nm}$, blue (B) $470 \mathrm{~nm}$, far-red (FR) $740 \mathrm{~nm}$, a combination of blue and red light (B: R 1:1), and natural light treatment (without any supplementary lighting) as a control. Supplemental light duration was 16 h/day (5 a.m. to 9 p.m.).

\section{Measurements}

Data were collected (after 15 days of providing supplemental light) to measure the growth characteristics such as plant height, stem length, no. of node and leaf, leaf length, leaf width, and plant fresh weight. After growth measurements, the samples were freezedried and prepared for chemical analysis.

\section{Determination of Ascorbic Acid}

A modified protocol reported by Gahler et al. was used to determine the content of ascorbic acid [14]. Fresh samples (10g) were mixed with $40 \mathrm{~mL}$ of $5 \%$ Metaphosphoric acid and blended to extract ascorbic acid. The mixtures were shaken at $250 \mathrm{rpm}$ for 5 minutes and then centrifuged at $3,000 \times \mathrm{g}$ for $10 \mathrm{~min}$. The supernatants were used to determine the concentration of ascorbic acid using the HPLC system equipped with a C18 column (Agilent Technologies 1200 Series), sample injects $3 \mu \mathrm{ml}$, maintained at 300C. The extract was eluted with mobile phase (HCN 5\%, DI water $95 \%$ with $0.1 \%$ formic acid) at a flow rate of $0.5 \mathrm{~mL} / \mathrm{min}$, run time 10 minutes. The absorbance of the eluant was measured at $254 \mathrm{~nm}$ and concentrations were determined against ascorbic acid standards (Mallinckrodt Baker, Inc., Phillipsburg).

\section{Total Phenolic Compounds}

The method of Singleton and Rossi was used to determine total phenolic compounds [15]. Briefly, freeze-dried samples (50 mg) extracted were with $10 \mathrm{~mL} 80 \%$ methanol and shaken at 240 rpm for $16 \mathrm{~h}$. After filtering $50 \mu \mathrm{L}$ of the methanolic extract was then mixed with $350 \mu \mathrm{L}$ of $\mathrm{H} 20$ and $200 \mu \mathrm{L}$ of $1 \mathrm{~N}$ Folin- Ciocalteu reagents (Sigma Chemical Co., St. Louis, Mo). The mixture was incubated for $1 \mathrm{~h}$ in $1.0 \mathrm{~mL}$ of $10 \% \mathrm{Na} 2 \mathrm{CO} 3$ at $250 \mathrm{C}$. The absorbance of the incubated mixture was then measured at $735 \mathrm{~nm}$ a UV-5000 VIS NIR spectrophotometer (Varian Technologies, Australia) with a standard curve to estimate gallic acid (Sigma Chemical Co., St. Louis, Mo.) equivalent (GAE) concentrations.

\section{Anthocyanin Analysis}

Freeze-dried samples (30 mg) were extracted with $5 \mathrm{~mL} 2 \%$ $\mathrm{HCl}$ in methanol for $36 \mathrm{~h}$. The liquid extract was separated by centrifugation at $1446 \times \mathrm{g}$ for $15 \mathrm{~min}$. For each sample, separate $400 \mu \mathrm{l}$ aliquots of extract were diluted to $2.0 \mathrm{~mL}$ with two different buffer solutions: potassium chloride buffer $(0.025, \mathrm{pH} 1.0)$ and sodium acetate buffer $(0.4 \mathrm{M}, \mathrm{pH} 4.5)$. After $15 \mathrm{~min}$ reaction, both solutions were filtered $(0.2 \mu \mathrm{m}$ pore size $)$ and the absorbance was measured at $515 \mathrm{~nm}$, where maximum absorption was confirmed in separate scans taken with UV-5000 VIS NIR spectrophotometer (Varian Technologies, Australia) and at $700 \mathrm{~nm}$ for haze correction. Total anthocyanin concentrations were expressed as cyaniding-3glucoside equivalent values, following the protocol described by Giusti and Wrolstad [16].

\section{Total Chlorophylls Content}

Fresh leaf tissue (100 mg) was extracted in $5 \mathrm{~mL} \mathrm{~N}, \mathrm{~N}$ dimethylformamide overnight. The absorbance of extraction solution was measured at $647 \mathrm{~nm}$ and $664 \mathrm{~nm}$ a UV-5000 VIS NIR spectrophotometer (Varian Tech., Australia). Chlorophyll concentration was calculated using the equations described by Moran [17].

\section{Statistical Analysis}

All data were analyzed by one way ANOVA and Duncan's multiple range test (DMRT) using MSTAT at 5\% level of significance.

\section{Results and Discussion}

\section{Effects of Supplemental Led Light Qualities on Growth Characteristics}

Table 1: Effects of supplemental LED light qualities on growth characteristics of buckwheat plants.

\begin{tabular}{|c|c|c|c|c|c|c|c|}
\hline Treatment & $\begin{array}{c}\text { Plant height } \\
\text { (cm) }\end{array}$ & $\begin{array}{c}\text { Stem length } \\
\text { (cm) }\end{array}$ & No.of node & No. of leaf & $\begin{array}{c}\text { Leaf length } \\
\text { (cm) }\end{array}$ & $\begin{array}{c}\text { Leaf width } \\
\text { (cm) }\end{array}$ & $\begin{array}{c}\text { Plant fresh } \\
\text { weight (g) }\end{array}$ \\
\hline Blue & $27.20 \mathrm{~b}^{\mathrm{z}}$ & $22.10 \mathrm{~b}$ & $2.0 \mathrm{a}$ & $4.30 \mathrm{~b}$ & $4.45 \mathrm{~b}$ & $2.68 \mathrm{c}$ & $2.83 \mathrm{a}$ \\
\hline Red & $25.13 \mathrm{~b}$ & $19.18 \mathrm{c}$ & $2.2 \mathrm{a}$ & $5.10 \mathrm{a}$ & $4.59 \mathrm{~b}$ & $3.23 \mathrm{~b}$ & $2.71 \mathrm{a}$ \\
\hline BR(1:1) & $29.65 \mathrm{a}$ & $20.05 \mathrm{c}$ & $2.2 \mathrm{a}$ & $4.70 \mathrm{~b}$ & $5.13 \mathrm{a}$ & $3.55 \mathrm{a}$ & $2.95 \mathrm{a}$ \\
\hline Far red & $29.01 \mathrm{a}$ & $25.06 \mathrm{a}$ & $2.1 \mathrm{a}$ & $3.70 \mathrm{c}$ & $4.21 \mathrm{c}$ & $2.43 \mathrm{c}$ & $1.86 \mathrm{~b}$ \\
\hline Control & $23.70 \mathrm{c}$ & $18.85 \mathrm{~d}$ & $2.3 \mathrm{a}$ & $3.22 \mathrm{c}$ & $4.10 \mathrm{c}$ & $2.79 \mathrm{c}$ & $1.80 \mathrm{~b}$ \\
\hline
\end{tabular}

Note: Z Mean separation within columns by DMRT at $5 \%$ level.

Growth characteristics of buckwheat plant were greatly influenced by different supplemental light treatments (Table 1). Plant height, Leaf length, leaf width, and plant fresh weight were increased by supplemental BR light. Far-red light increased the stem length and red light increased the leaf number compared to control. Blue and red lights are the major energy sources for plant growth and development [18]. Previously blue and red lights were proven as an effective lighting source to grow lettuce in a controlled environment [19]. Moreover, the positive effect of red light on the growth of perilla, tomato, chrysanthemum, and various herbs was studied [20]. It is widely understood that phytochrome photoreceptors enhanced the plant growth and development through activation of HY5`s gene which is stimulated by red light [21]. Martinez-Garcia et al. also illustrated that red light activates the phytochrome photoreceptor which enforces the relocalization of the nucleus and modulates gene expression [22]. 


\section{Effects of Supplemental Led Light Qualities on Phytochemical Contents}

Phytochemicals concentrations in buckwheat were significantly affected by different light treatments (Table 2). Among the treatment BR light significantly increased the ascorbic acid, anthocyanin, phenolic compound of buckwheat plant. Along with BR treatment, B and R treatment also showed good performance compared to control. Total chlorophyll content of buckwheat plants was profoundly increased by BR light treatment. Plant pigments have specific light absorption spectra. For instance; Chlorophyll has high light absorption at 400-500nm [23]. Blue light is abundantly absorbed by photosynthetic pigments and an important catalyst to increase the Chl contents in many plants; including lettuce and cucumber [24]. Results from the current study show that buckwheat plants have higher Chl content grown under BR light which is consistent with the findings of Son et al.[19]. Ma et al. illustrated that key gene activity of the enzyme in Chl pigment is stimulated by blue light resulting in higher pigments accumulation [25]. The combination of BR light was an important lighting source for the accumulation of polyphenol compounds such as; anthocyanin, ascorbic acid and total phenolic compound in lettuce [26].

Table 2: Effects of supplemental LED light qualities on phytochemical contents of buckwheat plants.

\begin{tabular}{|c|c|c|c|c|}
\hline Treatment & $\begin{array}{l}\text { Ascorbic acid } \\
\mathrm{mg} / 100 \mathrm{~g} \mathrm{FW}\end{array}$ & $\begin{array}{l}\text { Anthocyanin } \\
\text { mg/100 g DW }\end{array}$ & $\begin{array}{l}\text { Phenolic compound } \\
\text { mgGAE }^{\mathrm{x}} / \mathrm{g} \text { DW }\end{array}$ & $\begin{array}{c}\text { Chlorophyll content mg/g } \\
\text { FW }\end{array}$ \\
\hline Blue & $200.34 b^{Z}$ & $608.23 \mathrm{~b}$ & $710.87 \mathrm{~b}$ & $3.0 \mathrm{a}$ \\
\hline Red & $170.54 \mathrm{bc}$ & $610.71 \mathrm{~b}$ & $711.34 \mathrm{~b}$ & $3.3 \mathrm{a}$ \\
\hline $\mathrm{BR}(1: 1)$ & 249.23 a & 686.31 a & $782.36 \mathrm{a}$ & $3.7 \mathrm{a}$ \\
\hline Far red & $187.12 \mathrm{~b}$ & $400.43 \mathrm{~b}$ & $620.10 \mathrm{c}$ & $2.6 \mathrm{~b}$ \\
\hline Control & $100.43 c$ & $210.15 \mathrm{c}$ & $490.17 \mathrm{~d}$ & $2.1 \mathrm{c}$ \\
\hline
\end{tabular}

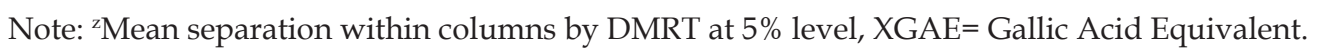

In addition, Son et al. stated that the content of polyphenols in the lettuce increased with the increasing blue light ratio. In our experiment BR light treatment increase the anthocyanin, phenolic compound and ascorbic acid in buckwheat plant support the previous findings [19]. Studies show that blue light is the most effective lighting source to synthesis anthocyanin by stimulating PAL (phenylalanine ammonia-lyase), CHS (chalcone synthesis) and DFR (dihydroflavonol-4-reductase) gene expression [27].

\section{Acknowledgment}

We are grateful to the Researchers of Rentia Research Group.

\section{References}

1. Kozai T, Fujiwara K, Kitaya Y (1994) Modeling, measurement and control in plant tissue culture. Environ Eff their Control Plant Tissue Cult 393: 63-76.

2. Bian ZH, Yang QC, Liu WK (2015) Effects of light quality on the accumulation of phytochemicals in vegetables produced in controlled environments: a review. J Sci Food Agric 95: 869-877.

3. Chang CL, Chang KP (2014) The growth response of leaf lettuce at different stages to multiple wavelength-band light-emitting diode lighting. Sci Hortic (Amsterdam) 179: 78-84.

4. Terashima I, Fujita T, Inoue T, Chow WS, Oguchi R (2009) Green light drives leaf photosynthesis more efficiently than red light in strong white light: revisiting the enigmatic question of why leaves are green. Plant cell Physiol 50: 684-697.

5. Brown CS, Schuerger AC, Sager JC (1995) Growth and photomorphogenesis of pepper plants under red light-emitting diodes with supplemental blue or far-red lighting. J Am Soc Hortic Sci 120: 808813.

6. Parks BM, Folta KM , Spalding EP (2001) Photocontrol of stem growth. Curr Opin Plant Biol 4: 436-440.

7. Matsuda R, Ohashi-Kaneko K, Fujiwara K, Goto E, Kurata K, et al. (2004) Photosynthetic characteristics of rice leaves grown under red light with or without supplemental blue light. Plant Cell Physiol 45: 1870-1874.
8. Macedo AF, Leal-Costa MV, Tavares ES, Lage CLS, Esquibel MA, et al. (2011) The effect of light quality on leaf production and development of in vitro-cultured plants of Alternanthera brasiliana Kuntze Environ Exp Bot 70: 43-50.

9. Schaxov AA (1993) Photoenergetics of plants and harvest (en ruso).

10. Kopsell DA, Kopsell DE (2008) Genetic and environmental factors affecting plant lutein/zeaxanthin. Agro Food Ind Hi-Tech 19: 44-46.

11. Giliberto L, Perrotta G, Pallara P, Weller JL, Fraser PD, et al. (2005) Manipulation of the blue light photoreceptor cryptochrome 2 in tomato affects vegetative development, flowering time, and fruit antioxidant content. Plant Physiol 137: 199-208.

12. Ramalho JC, Marques NC, Semedo JN, Matos MC, Quartin VL (2002) Photosynthetic performance and pigment composition of leaves from two tropical species is determined by light quality. Plant Biol 4:112-120.

13. Alokam S, Chinnappa CC, Reid DM (2002) Red/far-red light mediated stem elongation and anthocyanin accumulation in Stellaria longipes: differential response of alpine and prairie ecotypes. Can J Bot 80: 72-81.

14. Gahler S, Otto K, Böhm V (2003) Alterations of vitamin C, total phenolics, and antioxidant capacity as affected by processing tomatoes to different products. J Agric Food Chem 51: 7962-7968.

15. Singleton VL, Rossi JA (1965) Colorimetry of total phenolics with phosphomolybdic-phosphotungstic acid reagents. Am J Enol Vitic 16: 144-158.

16. Durst RW, Wrolstad RE (2005) Characterization and measurement of anthocyanins by UV-visible spectroscopy. Handb Anal food Chem p. 3345.

17. Moran R (1982) Formulae for determination of chlorophyllous pigments extracted with N, N-dimethylformamide. Plant Physiol 69: 1376-1381.

18. Kasajima S, Inoue N, Mahmud R, Kato M (2008) Developmental responses of wheat cv. Norin 61 to fluence rate of green light. Plant Prod Sci 11: 76-81.

19. Son KH (2013) Leaf shape, growth, and antioxidant phenolic compounds of two lettuce cultivars grown under various combinations of blue and red light-emitting diodes. HortScience 48: 988-995.

20. Heo JW, Kang DH, Bang HS, Hong SG, Chun CH, et al. (2012) Early growth, pigmentation, protein content, and phenylalanine ammonia-lyase 
activity of red curled lettuces grown under different lighting conditions. Korean J Hortic Sci Technol 30: 6-12.

21. Quail PH (2002) Photosensory perception and signalling in plant cells: new paradigms? Curr Opin Cell Biol 14: 180-188.

22. Martínez-García JF, Huq E, Quail PH (2000) Direct targeting of light signals to a promoter element-bound transcription factor. Science 288: 859-863.

23. Lin KH, Huang MY, Huang WD, Hsu MH, Yang ZW, et al. (2013) The effects of red, blue, and white light-emitting diodes on the growth, development, and edible quality of hydroponically grown lettuce (Lactuca sativa L var capitata) Sci Hortic (Amsterdam) 150: 86-91.

24. Hogewoning SW, Trouwborst G, Maljaars H, Poorter H, van Ieperen, et al. (2010) Blue light dose-responses of leaf photosynthesis, morphology,

ISSN: 2574-1241

DOI: $10.26717 / B J S T R .2019 .12 .002273$

Cheol Ho Park. Biomed J Sci \& Tech Res

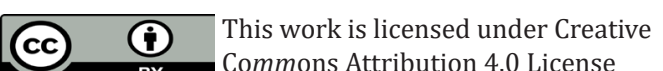

Submission Link: https://biomedres.us/submit-manuscript.php and chemical composition of Cucumis sativus grown under different combinations of red and blue light. J Exp Bot 61: 3107-3117.

25. Ma G, Zhang L, Kato M, Yamawaki K, Kiriiwa Y, et al. (2011) Effect of blue and red LED light irradiation on $\beta$-cryptoxanthin accumulation in the flavedo of citrus fruits. J Agric Food Chem 2011, 60: 197-201.

26. Johkan M, Shoji K, Goto F, Hashida S, Yoshihara T (2010) Blue lightemitting diode light irradiation of seedlings improves seedling quality and growth after transplanting in red leaf lettuce. HortScience 45: 18091814.

27. Meng X, Xing T, Wang X (2004) The role of light in the regulation of anthocyanin accumulation in Gerbera hybrida. Plant Growth Regul 44: 243.

$\begin{array}{ll}\text { BIOMEDICAL } & \text { Assets of Publishing with us } \\ \text { RESEARCHES } & \text { - Global archiving of articles } \\ \text { - Immediate, unrestricted online access }\end{array}$

